\title{
Investigation on Synthesis and Applications of Novel Polymeric Composites for the Removal of Heavy Metal Ion
}

\author{
RAJESWARI BALAKRISHNAN and SANTHI RADHAKRISHNAN²* \\ ${ }^{1} \mathrm{~K}$. Ramakrishnan College of Engineering, Samayapuram, Tiruchirappalli-621 112, Tamil Nadu, India. \\ 1,2PG and Research Department of Chemistry, Seethalakshmi Ramaswami College, \\ Affiliated to Bharathidasan University, Tiruchirappalli-620 002, Tamil Nadu, India. \\ *Corresponding author E-mail: santhichemsrc@gmail.com \\ http://dx.doi.org/10.13005/ojc/360417
}

(Received: July 07, 2020; Accepted: August 08, 2020)

\begin{abstract}
Conducting polymers were synthesized by doping polyaniline chloride with Schiff bases such as (E)-2-((4s-chlorobenzylidene)amino)-3-(3a,7a-dihydro-1H-indol-3-yl)propanoic acid (TP4CIB) and (E)-3-(3a,7a-dihydro-1H-indol-3-yl)-2-((2-hydroxy-3,5-diiodobenzylidene)amino) propanoic acid (TPDISA). A chemical oxidation method using potassium persulphate as an oxidising agent was followed for the preparation of polymers. The prepared polymers were characterized by UVVisible, FTIR and $\mathrm{H}^{1}$ NMR spectroscopic techniques. The adsorption characteristics of Polymeric composites for the removal of mercuric ion was studied through batch process. Sorption isotherms were constructed using Langmuir, Freundlich, Dubinin Radush Kevich, Temkin and Redlich Peterson models. SEM micrograph, PXRD and EDX spectra were also recorded to confirm the metal ion adsorption on the surface of investigated composites.
\end{abstract}

Keywords: Adsorption, Polymeric composite, Mercuric chloride, Tryptophan, Schiff bases.

\section{INTRODUCTION}

Environmental contamination due to minerals and heavy metals is the major challenging problem in our country. The concentration of heavy metals due to industrial and agricultural waste materials have been increased to the levels of high risk $^{1-4}$. Among the various metals like lead, mercury, chromium, arsenic, nickel, uranium, selenium, silver, cadmium, zinc and gold present in industrial waste water, discharge of $\mathrm{Hg}$ (II) ions cause severe environmental contamination as it is non-degradable and bio-accumulate in nature ${ }^{5-8}$. Fertilizers industry, power generation plants, paper manufacturing, rubber processing and oil refineries are found to be the great sources for the emission of mercury into the universe. Health issues such as dialysis and problem in central nervous system occur due to circulation of mercury in the blood and storage in brain, liver, spleen, kidney and bone. Hence it is right time to carryout the research on the removal of mercuric ion from the environment. Though the number of methods such as reverse osmosis, floatation, adsorption, coagulation, flocculation, electrodialysis, chemical precipitation, nanofiltration, ion exchange, ultrafiltration, chemical precipitation and nanofiltration

This is an Open Access article licensed under a Creative Commons license: Attribution 4.0 International (CC- BY). Published by Oriental Scientific Publishing Company @ 2018

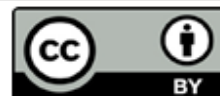


have been practiced for discarding the heavy metals, adsorption is an economical and more suitable one as it is simple to perform, easy to operate at low budget for the removal of toxic contaminants. Hence an attempt has been made to synthesize a novel organic polymer by doping polyaniline chloride with the potential Schiff bases. The synthesized organic polymers have been characterized by UV-Visible, FTIR and $\mathrm{H}^{1} \mathrm{NMR}$ spectroscopy. The adsorption characteristics of PANI-CI composite for the removal of mercuric ion was studied through batch process ${ }^{9-11}$. Langmuir, Freundlich, Dubinin Radushkevich, Temkin and Redlich Peterson isotherms have been verified. Adsorption of the metal on the organic polymer has been confirmed by PXRD, SEM analysis and EDX spectra.

\section{MATERIALS AND METHODS}

The reagents and solvents were used as such(AR grade). Aniline $(\mathrm{BDH})$ was distilled under reduced pressure before use. All the experiments were carried out using Double distilled water. Hydrochloric acid \& sodium hydroxide solutions were used to study sorption behavior of the solutions $(\mathrm{BDH})$ at different $\mathrm{pH}$.

\section{Preparation of Schiff bases}

The Schiff bases (E)-2-((4s-chlorobenzylidene)amino)-3-(3a,7a-dihydro-1H-indol-3-yl) propanoic acid (TP4CIB) and (E)-3-(3a,7a-dihydro1H-indol-3-yl)-2-((2-hydroxy-3,5-diiodobenzylidene) amino)propanoic acid (TPDISA) were prepared by the condensation of tryptophan $(2.04 \mathrm{~g})$ with equivalent amount of 4-chlorobenzaldehyde and 3,5diiodosalicylaldehyde respectively, The reaction was performed in presence of an acid and refluxed for 4 hours. The solid product formed was filtered at the suction pump and washed with ethanol. Then it was dried over anhydrous $\mathrm{CaCl}_{2}$ in a vaccum desiccator and recrystallised with alcohol.

\section{Preparation of polyaniline hydrochloride}

Aniline $(0.1 \mathrm{M})$ was dissolved in aqueous solution of hydrochloric acid (1M). The mixture was stirred using a magnetic stirrer and $50 \mathrm{~mL}$ of potassium persulphate $(0.1 \mathrm{M})$ was added drop wise to the aniline-acid mixture for about two hours with continuous stirring at $303 \mathrm{~K}$. The contents were stirred further for $30 \mathrm{~min}$ to ensure complete polymerization. A dark green coloured PANI-CI thus formed was filtered using a Whatmann No. 1 filter paper. The excess acid content and oligomers of aniline were removed by repeated washings with distilled water, ethanol, acetone and diethyl ether ${ }^{11}$. The green coloured polymer obtained was dried in an air oven for four hours till constant weight was reached.

The colour changes that appeared during the addition of potassium persulphate is given below.

Straw yellow $\rightarrow$ yellow $\rightarrow$ brown $\rightarrow$ green colour

\section{Preparation of polymeric composite}

PANI-CI (1 g) and Schiff base (TP4CIB, TPDISA) (1 g) were mixed together and suspended in $15 \mathrm{~mL}$ of diethyl ether and sonicated in an ultra sonic cleaning bath (NEY, $50 \mathrm{Khz}$ ) for 30 minutes. The slurry obtained was centrifuged and the supernatant liquid was removed. The resulting product was washed with ether and centrifuged. The dark green coloured mass obtained was dried in a vacuum desiccator to get a free flowing powder.

\section{Spectral analysis}

UV-Visible spectra of the polymeric composites were recorded in DMSO using Lambda 35 Perkin Elmer UV-Visible spectrophotometer (200-1100nm). FTIR spectra were recorded as $\mathrm{KBr}$ pellets using a Perkin Elmer FTIR spectrometer in the range of $4000-400 \mathrm{~cm}^{-1}$. $\mathrm{H}^{1} \mathrm{NMR}$ spectra were carried out in DMSO on a Bruker $400 \mathrm{MHz}$ Nuclear Magnetic Resonance spectrometer. The Powder X-ray diffraction pattern of mercuric chloride after adsorption was performed using Bruker D8 X-ray diffractometer, Germany at a scan rate of 1 step/ second. The sample was irradiated with $\mathrm{CuK} \alpha$ radiation and studied in the range $20-80^{\circ}(2 \theta)$ with a step size of $0.001^{\circ}$. The SEM and EDX spectra of pani matrix were studied using Field Emission Scanning Electron Microscope.

\section{Sorption experiments}

Polymeric composites (2 $\mathrm{mg}$ ) were suspended in a solution of mercuric chloride $(10 \mathrm{~mL}, 0.02 \mathrm{M})$ and sonicated for half an hour at room temperature and centrifuged. Five $\mathrm{mL}$ of the supernatant liquid was pipetted out and titrated against $\mathrm{KI}$ solution by conductometric method ${ }^{11,13}$. The mercuric chloride concentration in the centrifugate was calculated from the plot of conductance Vs volume of $\mathrm{KI}$. The sorption curves were constructed from the concentration of mercuric chloride after adsorption $\left(\mathrm{C}_{\mathrm{e}}\right)$. The initial concentrations $\left(\mathrm{C}_{\mathrm{o}}\right)$ were in the range of $0.01-0.05 \mathrm{M}$. 


\section{Effect of temperature}

The adsorption of $\mathrm{HgCl}_{2}$ solutions on Polymeric composites were studied at $5^{\circ} \mathrm{C}$ intervals ranging from $303-318 \mathrm{~K}$ to understand the temperature effect. Polymeric composites (2 mg) and $\mathrm{HgCl}_{2}(10 \mathrm{~mL}, 0.02 \mathrm{M})$ were sonicated for $30 \mathrm{~min}$, after which the concentration of mercuric chloride was determined.

\section{Effect of contact time}

A known amount $(2 \mathrm{mg})$ of adsorbent was sonicated with $10 \mathrm{~mL}$ of $0.02 \mathrm{M}$ of $\mathrm{HgCl}_{2}$ solution at different equilibrium time (10-60 minutes). The optimum time required for maximum adsorption of $\mathrm{HgCl}_{2}$ was found to be 30 minutes.

\section{Effect of $\mathrm{pH}$}

The influence of $\mathrm{pH}$ on the adsorption capacity of polymeric composites were investigated in the $\mathrm{pH}$ range $1-13$. The compounds (10 $\mathrm{mg}$ ) were suspended in $2.5 \mathrm{~mL}$ of conductivity water. $\mathrm{HgCl}_{2}$ $(2.5 \mathrm{~mL}, 0.05 \mathrm{M})$ and hydrochloric acid $\left(10^{-1}\right.$ to $\left.10^{-6} \mathrm{M}\right)$ were added and sonicated for $30 \mathrm{~min}$ to understand adsorption behaviour in low $\mathrm{pH}$. Similarly, $\mathrm{NaOH}$ solutions $\left(10^{-1}\right.$ to $\left.10^{-6} \mathrm{M}\right)$ were used for the study at alkaline $\mathrm{pH}$.

\section{RESULTS AND DISCUSSION}

Novel organic PANI composites polyaniline chloride-(E)-2-((4s-chlorobenzylidene)amino)-3-(3a, 7a-dihydro-1H-indol-3-yl)propanoic acid (PTP4CIB) and polyanilinechloride-(E)-3-(3a,7a-dihydro-1Hindol-3-yl)-2-((2-hydroxy-3,5-diiodobenzylidene) amino)propanoic acid (PTPDISA) were prepared, characterized by UV-Visible, FTIR and proton NMR spectra and compared for their adsorption capacity.

\section{UV-Visible spectra}

Electronic spectra of the composites exhibit two bands from $290 \mathrm{~nm}$ to $357 \mathrm{~nm}$ due to $\pi-\pi^{*}$ transitions in benzenoid rings and carbonyl present in carboxylic acid group of tryptophan moiety while polyaniline hydrochloride shows absorptions ${ }^{11}$ at 310 and $583 \mathrm{~nm}$. This shift in $\lambda_{\max }$ value to lower wavelength confirms the doping of schiff bases on polymer. A small shift observed in both the compounds confirms the adsorption of mercuric ion.

\section{Table 1: UV-Visible spectral analysis of} polymer composites

\begin{tabular}{cc}
\hline Name of the compound & $\Lambda_{\max }(\mathrm{nm})$ \\
\hline PTP4CIB & 301,329 \\
PTP4CIB- HgCl & 299,329 \\
PTPDISA & 297,357 \\
PTPDISA-HgCl & 298,363 \\
PANI-Cl & 310,583 \\
PANI-Cl- $\mathrm{HgCl}_{2}$ & 260,602 \\
\hline
\end{tabular}

\section{FTIR spectra}

The presence of absorption bands in the range $3500-4000 \mathrm{~cm}^{-1}$ may be ascribed to $\mathrm{OH}$ stretching frequency of $-\mathrm{COOH}$ group of tryptophan molecule in schiff base doped on PANI chloride. Appearance of bands at $1645-1656 \mathrm{~cm}^{-1}$ due to $\mathrm{CH}=\mathrm{N}$ stretching vibrations of imines confirms the doping of schiff base on polymer. The composites exhibit peaks between $2312-2358 \mathrm{~cm}^{-1}$ due to the presence of iminium sites on PANI matrix. The vibrations around $1487-1514 \mathrm{~cm}^{-1}$ indicate the signature peaks of the PANI back bone arising due to the stretching modes of the imino benzenoid rings. The broad peaks in the region 1000-1100 $\mathrm{cm}^{-1}$ may be attributed to $\mathrm{C}-\mathrm{N}$ stretching modes of primary amine. The bands around $940-990 \mathrm{~cm}^{-1}$ are generally assigned to bending mode of $\mathrm{O}-\mathrm{H}$ bond. The bending vibrations of the PANI back bone are observed around 600-690 $\mathrm{cm}^{-1}$. Both PTP4CIB and PTPDISA exhibit a band at about $3300-3400 \mathrm{~cm}^{-1}$ due to $\mathrm{N}-\mathrm{H}$ stretching of amine present in schiff base. A peak at $597 \mathrm{~cm}^{-1}$ due to $\mathrm{C}-\mathrm{Cl}$ and 555 due to $\mathrm{C}-\mathrm{I}$ further supports the presence of schiff base on the composite. The peaks at $1224 \mathrm{~cm}^{-1}, 1261 \mathrm{~cm}^{-1}$ and $1004 \mathrm{~cm}^{-1}$ may be attributed to $\mathrm{C}-\mathrm{N}$ stretching vibration.

Table 2: FTIR spectral analysis of polymeric composites

\begin{tabular}{ccccccccc}
\hline Name of the polymer & $v N-H$ & $v O-H$ & $v$ C-H & $v$ C=N & $v C-N$ & $v C-H$ & $\delta C-C$ & $\delta C-H$ \\
\hline PTP4CIB & 3732 & 3400 & 2358 & 1654 & - & $1265-1008$ & 947,642 & $597-553$ \\
PTP4CIB-HgCl & $3857-3739$ & - & $2987-, 2318$ & $1701-1645$ & 1514 & 1049 & $977-921$ & $559-513$ \\
PTPDISA & $3859-3741$ & - & $2380-2312$ & $1683-1649$ & $1514-1425$ & 1004 & 947 & $599-555$ \\
PTPDISA-HgCl & - & $3377-3000$ & $2353-2154$ & 1651 & 1363 & 1093 & 991 & $495-, 459$ \\
PANI-Cl & $3820-3713$ & 3423 & $2985-2358$ & $1692-1588$ & 1487 & 1239 & 798 \\
\hline
\end{tabular}




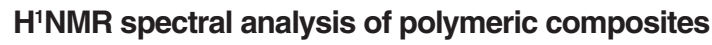
Proton $\mathrm{H}^{1} \mathrm{NMR}$ spectral data (Fig.1a, b) further supports the doping of imines on pani back bone. Signals at $10.1 \& 9.98$ ppm for both the compounds envisage the presence of carboxylic acid proton in indole derivative of adsorbents. The signals around 8.0 and 8.3 are due to imine protons of PTP4CIB and PTPDISA. Appearance of multiplets in the range 6.6-7.7 for both the composites may be attributed to $\mathrm{NH} \& \mathrm{CH}$ protons of the aromatic rings.

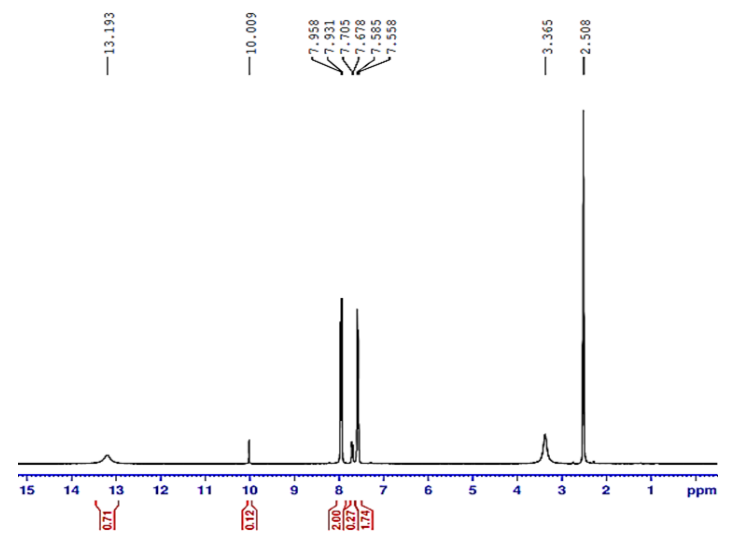

Fig. 1a. Proton NMR spectra of PTP4CIB

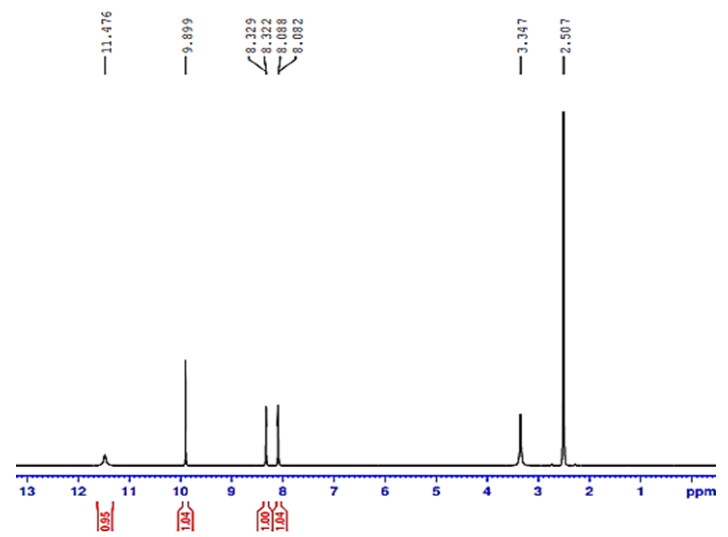

Fig. 1b. Proton NMR spectra of PTPDISA

\section{Adsorption studies of mercuric chloride on PANI} composites

Experiments on adsorption of mercuric ion by two new organic adsorbents were carried out by batch process. Concentration of mercuric ion in the filtrate after adsorption was measured conductometrically.

\section{Effect of variation of mercuric ion}

Langmuir, Freundlich, Temkin, Dubinin Radush-Kevich and Redlich-Peterson models are employed to evaluate the adsorption capacity and the surface properties of adsorbent related to adsorption $^{14-16}$.

\section{Langmuir Isotherm}

This model is used to calculate the amount of $\mathrm{Hg}^{2+}$ ions adsorbed $\left(\mathrm{q}_{\mathrm{m}}\right)$ by Polymeric composites. From the plot of $1 / q_{e}$ vs $1 / C_{e}$, it is observed that the process obeys the Langmuir model. The Langmuir constants $\mathrm{q}_{m}$ and $\mathrm{K}_{\mathrm{L}}$ determined from the slope and intercept of the plot are presented in Table 3.

$$
1 / q_{e}=1 / K_{L} q_{m} C_{e}+1 / q_{m}
$$

In Langmuir equation( 1 ) $q_{m}$ is the maximum monolayer adsorption capacity of the adsorbent (mg/g).

The essential characteristics of the Langmuir isotherm can be expressed by a dimensionless constant called the separation factor $R_{L}$.

$$
R_{L}=1 / 1+K_{L} C_{0}
$$

Where $\mathrm{K}_{\mathrm{L}}$ is Langmuir constant $\left(\mathrm{mg} \mathrm{g}^{-1}\right)$ and $\mathrm{C}_{0}$ is initial concentration of adsorbate $\left(\mathrm{mg} \mathrm{g}^{-1}\right)$.

The $R_{L}$ values indicate that the adsorption process using the adsorbents under investigation is favourable $\left(0<R_{L}<1\right)^{17} . q_{m}$ value is greater $(0.884$ $\mathrm{mg} / \mathrm{g})$ for PTP4CIB composite with $\mathrm{K}_{\mathrm{L}}(11.06 \mathrm{~L} / \mathrm{g})$ and hence the Langmuir model is best fitted for PTP4CIB in comparison with PTPDISA.

\section{Freundlich isotherm}

The Freundlich adsorption isotherm gives the sorption equilibrium for both monolayer and multilayer adsorption and it is evidenced by equation (3).

$\log q_{e}=\log k_{F}+1 / n \log C_{e}$

Where $n$ is related to the intensity of adsorption and $k_{F}$ denotes adsorption capacity. From the plot of $\log q_{e} V s \log C_{e}$ the Freundlich isotherm constant $k_{F}$ (sorption capacity) and $1 / n$ (intensity of sorption) are calculated ${ }^{17-21}$. The correlation coefficients $R^{2}$ are shown in Table 3. The higher value of $k_{F}$ is found for PTPDISA $\left(k_{F}=1.873\right)$ indicating multilayered formation.

\section{Dubinin Radush-kevich isotherm}

The linear form of DR isotherm is represented by equation (4). A plot of Inqe $V s \varepsilon^{2}$ is found to be a linear trace and the constants $q_{D}$ and $B$ calculated from the slope and intercept are presented in Table 3. Dubinin Radush-kevich (DR) isotherm has been usually applied to know whether the adsorption of metal ion is physisorption or chemisorption. The isotherm constant $B$ is relatively 
higher for PTP4CIB (2.198). From this model it is found that physical nature of adsorption is more suitable for both the composites.

$\ln \mathrm{q}_{\mathrm{e}}=\ln \mathrm{q}_{\mathrm{D}}-\mathrm{B} \varepsilon^{2}$

\section{Temkin isotherm}

This isotherm is used to understand the adsorbent-adsorbate interactions. The linearity of Temkin isotherm is represented by equation (5).

$\mathrm{q}_{\mathrm{e}}=\mathrm{B}_{\mathrm{T}} \ln \mathrm{A}_{\mathrm{T}}+\mathrm{B}_{\mathrm{T}} \ln \mathrm{C}_{\mathrm{e}}$

The Temkin isotherm equilibrium binding constant $\left(A_{T}\right)$ and the Temkin heat of adsorption $\left(B_{T}\right)$ are calculated using the slope and intercept of the plot $q_{e} V s \ln C_{e}$. Temkin heat of adsorption $B_{T}$ is found to be high for PTP4CIB. The higher values of binding constants are observed for PTP4CIB.

\section{Redlich-Peterson isotherm}

Redlich-Peterson isotherm can be applied for homogeneous or heterogeneous systems due to its versatility ${ }^{17-21}$. The mathematical relation of this isotherm is given by equation (6).

$$
\mathrm{C}_{\mathrm{e}} / \mathrm{q}_{\mathrm{e}}=1 / \mathrm{K}_{\mathrm{RP}}+\alpha_{\mathrm{RP}} / \mathrm{K}_{\mathrm{RP}} \mathrm{C}_{\mathrm{e}} \beta
$$

Where, $\mathrm{K}_{\mathrm{RP}} \alpha_{\mathrm{RP}}$ and $\beta$ are constants. $A$ plot of $\mathrm{C}_{e} / \mathrm{q}_{\mathrm{e}}$ Vs $\mathrm{C}_{\mathrm{e}}$ is linear and the constants $\mathrm{K}_{\mathrm{RP}}$ and $\alpha_{\mathrm{RP}}$ are determined from the slope and intercept (Table 3). $\mathrm{K}_{\mathrm{RP}}$ value of 4.878 is found for PTPDISA $\left(R^{2}=0.993\right)$ indicating heterogeneous adsorption. The $\mathrm{K}_{\mathrm{RP}}$ value of 0.9115 for PTP4CIB suggesting homogeneous adsorption.

Table 3: Adsorption studies of $\mathrm{HgCl}_{2}$ on Polymeric composites

\begin{tabular}{lccc}
\hline Isotherm type & Parameter & PTP4CIB & PTPDISA \\
\hline Langmuir & $\mathrm{K}_{\mathrm{L}}$ & 11.06 & 3.03 \\
& $\mathrm{q}_{\mathrm{m}}$ & 0.884 & 0.549 \\
& $\mathrm{R}^{2}$ & 0.992 & 0.952 \\
& $\mathrm{R}$ & 0.995 & 0.975 \\
Freundlich & $\mathrm{R}_{\mathrm{L}}$ & 0.016 & 0.053 \\
& $\mathrm{~N}$ & 0.789 & 1.972 \\
& $\mathrm{k}_{\mathrm{F}}(\mathrm{L} / \mathrm{mg})$ & 0.600 & 1.873 \\
& $\mathrm{R}^{2}$ & 0.927 & 0.966 \\
Dubinin Radushkevich & $\mathrm{R}$ & 0.962 & 0.982 \\
& $\mathrm{q}_{\mathrm{D}}(\mathrm{mg} / \mathrm{g})$ & 5.926 & 5.185 \\
& $\mathrm{~B}$ & 2.198 & 1.580 \\
& $\mathrm{R}^{2}$ & 0.907 & 0.938 \\
Temkin & $\mathrm{R}$ & 0.952 & 0.968 \\
& $\mathrm{~B}_{\mathrm{T}}(\mathrm{L} / \mathrm{mg})$ & 0.042 & 0.037 \\
& $\mathrm{~A}_{\mathrm{T}}(\mathrm{KJ} / \mathrm{mol})$ & 0.025 & 0.023 \\
& $\mathrm{R}^{2}$ & 0.935 & 0.900 \\
& $\mathrm{R}$ & 0.966 & 0.948 \\
Redlich Peterson & $\mathrm{K}_{\mathrm{RP}}(\mathrm{L} / \mathrm{mg})$ & 0.911 & 4.878 \\
& $\alpha_{\mathrm{RP}}$ & 28.11 & 92 \\
& $\mathrm{R}^{2}$ & 0.905 & 0.988 \\
& $\mathrm{R}$ & 0.951 & 0.993 \\
\hline
\end{tabular}

\section{Effect of variation of Temperature}

In order to verify the influence of temperature variation on the process of adsorption, the experiment was conducted at the temperatures between $303-318 \mathrm{~K}$. The distribution coefficients $\left(\mathrm{K}_{\mathrm{d}}\right)$ are calculated ${ }^{22}$ using the equation (7).

$\mathrm{K}_{\mathrm{d}}=\mathrm{q}_{\mathrm{e}} / \mathrm{C}_{\mathrm{e}}$

Where $q_{e}$-the amount of metal adsorbed at equilibrium and $\mathrm{C}_{\mathrm{e}}$-equilibrium concentration of metal ions in solution.

The standard free energy change $\left(\Delta \mathrm{G}^{\circ}\right)$ is calculated from Van't Hoff equation (8).

$\Delta \mathrm{G}^{\circ}=-\mathrm{RT} \ln \mathrm{K}_{\mathrm{d}}$

Where $\mathrm{R}=$ universal gas constant $(8.314 \mathrm{~J}$ $\left.\mathrm{mol}^{-1} \mathrm{~K}^{-1}\right)$.

The slope and intercept values of the plot of InKd Vs $1 / T$ are used to determine the values of $\Delta \mathrm{H}^{\circ}$ and $\Delta \mathrm{S}^{\circ}$.

$\ln K_{d}=-\Delta H \% / R T+\Delta S \% R$

Thermodynamic parameters ${ }^{23,24}$ such as standard free energy of adsorption $\left(\Delta \mathrm{G}^{\circ}\right)$, standard enthalpy of adsorption $\left(\Delta \mathrm{H}^{\circ}\right)$ and the standard entropy of adsorption $\left(\Delta S^{\circ}\right)$ are very helpful in understanding the adsorbent-adsorbate system. The negative value of $\Delta \mathrm{G}^{\circ}$ indicates the feasibility of adsorption process (Table 4). The exothermic nature of adsorption is understood from $\Delta \mathrm{H}^{\circ}$ values. The positive value of $\Delta \mathrm{S}^{\circ}$ for both the investigated polymers shows the spontaneity of the adsorption process ${ }^{19}$. It also shows the affinity of adsorbent towards adsorbate species.

Table 4: Thermodynamic parameters for the adsorption of $\mathrm{HgCl}_{2}$ on Polymeric composites

\begin{tabular}{ccccc}
\hline $\begin{array}{c}\text { Name of the } \\
\text { pani composite }\end{array}$ & $1 / \mathrm{T}^{*} 10^{-3}$ & $\begin{array}{c}\Delta \mathrm{G}^{\circ} \\
(\mathrm{KJ} / \mathrm{mole})\end{array}$ & $\begin{array}{c}\Delta \mathrm{H}^{\circ} \\
(\mathrm{KJ} / \mathrm{mole})\end{array}$ & $\begin{array}{c}\Delta \mathrm{S}^{\circ} \\
(\mathrm{J} / \mathrm{mole})\end{array}$ \\
\hline PTP4CIB & 3.3 & -3.03 & -21.44 & 6.881 \\
& 3.24 & -2.249 & & \\
& 3.19 & -1.66 & & \\
PTPDISA & 3.14 & -0.154 & & \\
& 3.3 & -2.767 & & \\
& 3.24 & -0.951 & -25.68 & \\
& 3.19 & -0.58 & & \\
\hline
\end{tabular}

Powder XRD study

The XRD patterns show several sharp peaks (Fig. $2 \mathrm{a}$ ) in the region of $10^{\circ}-60^{\circ}(2 \theta)$ with a 
step size of $0.001^{\circ}$. The average particle size (D) is calculated from Debye Scherrer's formula (10).

$\mathrm{D}=0.9 \lambda / \beta \cos \theta$

Where $\lambda=$ wavelength of $\mathrm{CuK} \alpha$ radiation

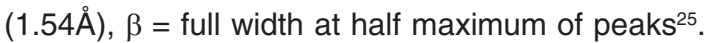
The Particle size varies from $40-160 \mathrm{~nm}$ for the composites. The sharp peaks in the region of 20-62 illustrate the crystalline nature of polymeric composite (Figure 2a,b).

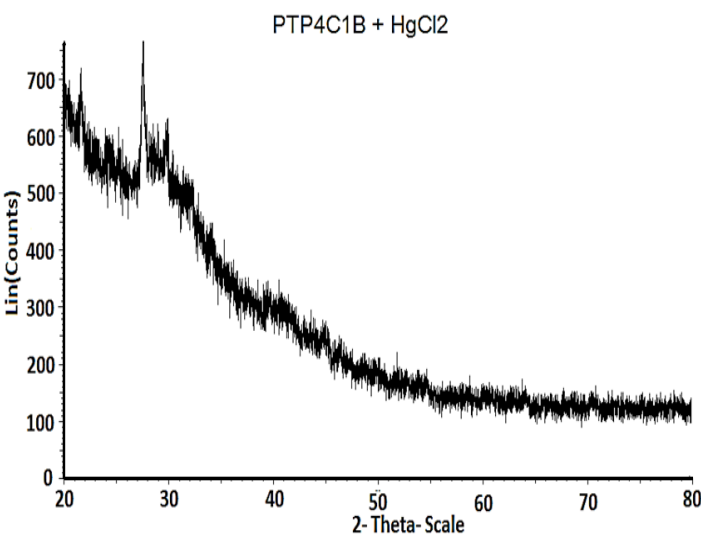

Fig. 2a. Powder XRD spectrum-after adsorption of mercuric chloride on PTP4CIB

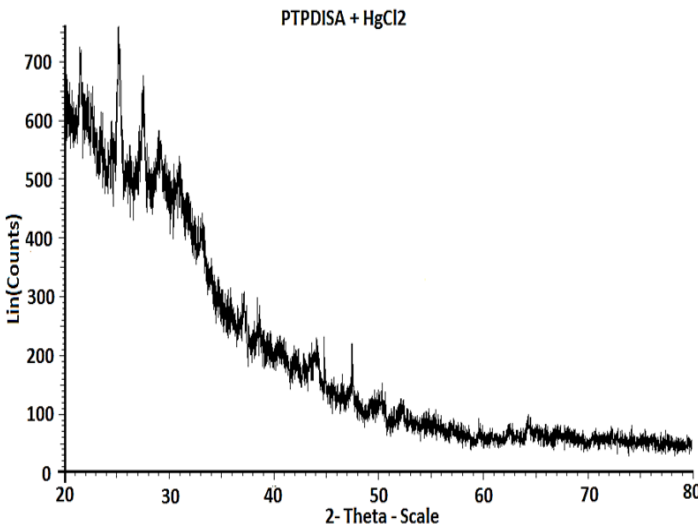

Fig. 2b. Powder XRD spectrum-after adsorption of mercuric chloride on PTPDISA

\section{SEM analysis}

The difference in morphology is observed in SEM picture of Polymeric composites before and after adsorption of $\mathrm{HgCl}_{2}$ confirming the adsorption of metal ion (Fig. 3a, d). The particles are of small spherical in nature before adsorption while after adsorption the particles are larger, rod shaped and non-uniform in their size distribution. The embedded molecules of $\mathrm{HgCl}_{2}$ on Pani backbone are clearly visible.

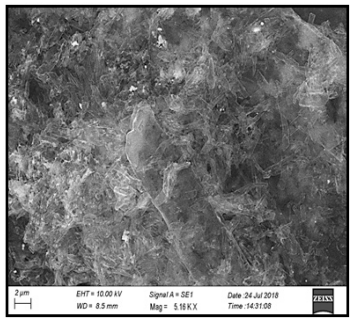

(a)

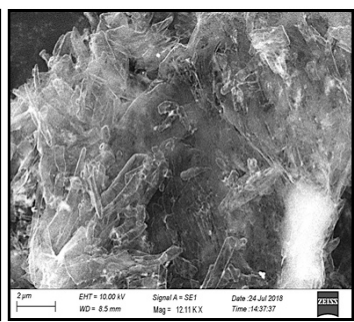

(b)
Fig. 3a,b. SEM analysis-before and after adsorption of $\mathrm{HgCl}_{2}$ on PTP4CIB composite

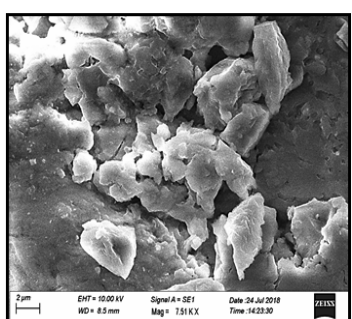

(c)

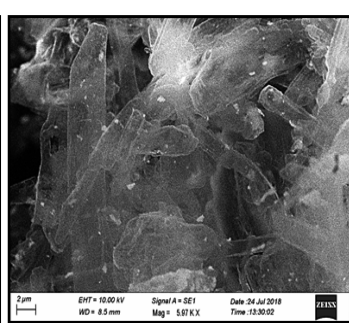

(d)
Fig. 3c,d. SEM analysis-before and after adsorption of $\mathrm{HgCl}_{2}$ on PTPDISA composite

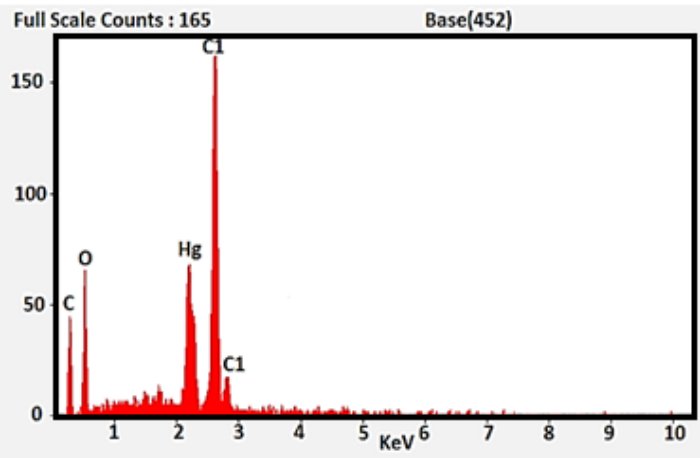

(a)

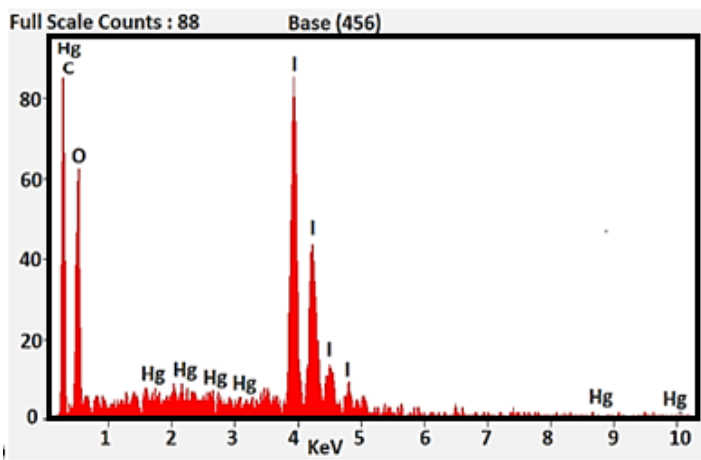

(b)

Fig. 4 EDX spectra of polymers after adsorption a) PTP4CIB b) PTPDISA

\section{EDX analysis}

Energy dispersive $\mathrm{X}$-ray technique is used 
to find out the elemental composition and chemical characterisation of samples. The EDX spectra of the chosen composites present sharp peaks at $2-3 \mathrm{KeV}$ strongly supporting the adsorption of mercuric ions on pani matrix (Figure 4a,b).

\section{CONCLUSION}

Two Schiff base (TP4CIB and TPDISA) doped polymer composites(PTP4CIB amd PTPDISA) were prepared and characterized by UV-Visible, FT-IR and proton $\mathrm{H}^{1} \mathrm{NMR}$ spectroscopic techniques. The adsorption behaviour of the adsorbents were understood from Langmuir, Freundlich, Dubinin Radushkevich, Temkin and Redlich Peterson isotherm models. It is observed that adsorption of mercuric chloride on both the new polymeric compounds is a favorable process as the adsorbents are best fitted for all the isotherms studied. The thermodynamic parameters calculated in the present work further confirms the feasibility of the adsorption process. SEM micrograph, PXRD and EDX spectra recorded after adsorption are the supporting tools to indicate the adsorption of mercuric ion on the chosen adsorbents.

\section{ACKNOWLEDGEMENT}

The authors express their heartfelt thanks to the Management, Principal, Vice principal of Seethalakshmi Ramaswami College, Trichy for the facilities provided and the continuous encouragement to carry out this research work.

\section{Conflict of Interest}

The authors decided that there is no conflict of interest regarding the publication of this paper.

\section{REFERENCES}

1. Babu Rao, G.; Krishna Prasad, M.; Murthy, Ch. V. R.; Int. J. Chem. Sci., 2015, 13, 1893-1910.

2. Nishiyama, Y.; Hanafusa, T.; Yamashita, J.; Yamamoto, Y.; Ono, T.; J. Radioanal Nucl. Chem., 2016, 307, 1279-1285.

3. Dalia, M.; Saad, Ewa. M.; Cukrowska; Appl. water Sci., 2013, 3, 527-534.

4. Saad, D.W; Cukrowska, E. M.; Tutu, H.; Appl. Water Sci., 2013, 3, 527-534.

5. Bayazeed, H.; Abdullah, ; Yousif, M. Salh.; Orient. J. Chem., 2010, 26, 763-773.

6. Qin, Li.; Li Sun.;Ya Zhang.;Yan Qian.; Jianping Zhai.; Desalination., 2011, 266, 188-194.

7. Iqbal, S. A.; Sibi Jose.; Ishaq Zaafrany; Orient. J. Chem., 2012, 28, 613-618.

8. Padmavathy, K. S.; Madhu, G.; Haseena, P.V.; Procedia Technology., 2016, 24, 585-594.

9. Joseph, A.; Ramamurthy, P. C.; Subramanian, S.; J. Appl. Polymer Sci., 2012, 123, 526-534.

10. Vivekanandan, J.; Ponnusamy, V.; Mahudeswaran, A.; Vijayanand, P. S.; Scholars research library, Archives of applied science research., 2011, 3, 147-153.

11. Dhivya, C.; Vandarkuzhali, S. A. A.; Santhi, R.; Radha, N.; Indian J. Appl. Res., 2013, 6, 62.

12. Rajeswari, B.; Santhi, R.; Radha, N.; International Journal of Research and Analytical Reviews., 2018, 5, 25-30.

13. Abu nasar.; Fouzia Mashkor.; Environmental science and pollution research., 2019, 26, 5333-5356.
14. Ayawei, N.; Godwin, J.; Wankasi, D.; Int. J. Chem. Sci., 2015, 13, 1197-1217.

15. Djebbar, M.; Djafri, F.; Bouchekara, M.; Djafri, A.; Appl Water sci., 2012, 2, 77-86.

16. Singh, V.K.; Soni, A.B.; Singh, R.K.; Int.J.Chem. Sci., 2016, 14, 2116-2138.

17. Nethaji, S.; Sivasamy, A.; Mandal, A. B.; Int. J. Envir. Sci. Technol., 2013, 10, 231-242.

18. Moftakhar, M. K.; Yaftian, M.R.; Ghorbanloo, M.; Int. J. Environ. Sci.Technol., 2016, 13, 1707-1722.

19. Jameer Ahammad, S.; Sumithra, S.; Subha, R.; International Journal of chemical scinces., 2017, 15, 161-172.

20. Nimibofo Ayawei.; Augustus Newton Ebelegi.; Donbebe wankasi.; Hindawi Journal of Chemistry., 2017, 1-17.

21. Mustapha, S.; Shuaib, D.T.; Nasirudeen, M.B.; Applied water science., 2019, 9, 142.

22. Renu, Madhu Agarwar, Singh, K.; Journal of water reuse and desalination., 2017.

23. Ayawei, N.; Ekubo, A.T.; Wankasi, D.; Dikio, E.D.; Orient. J. Chem., 2015, 31, 1307-1318.

24. Reza Amini.; Nizomov, Z.; Razazi, M.; Ganiev, I.N.; Obidov, Z.R.; Orient. J. Chem., 2012, 28, 841-846.

25. Madavan, R.; Murugesan, M.; Manikavasakam, K.; Sathish, R.; Manikandan, R.; Savariraj Sagayam, C.; Brindha, P.; International Journal of Pharmacy and Pharmaceutical Sciences., 2012, 4, 163-166. 